Iranian Journal of Pathology | ISSN: 2345-3656

\title{
Squamous Cell Differentiation in Metastatic Papillary Thyroid Carcinoma: Metaplastic Reversion or Progression?
}

\author{
Adriana Handra-Luca ${ }^{1,2}$ \\ 1. APHP GHU Avicenne, Bobigny, France \\ 2. Université Paris Nord Sorbonne Cite, Bobigny, France
}

\begin{tabular}{c}
\hline KEYWORDS \\
\hline Thyroid Cancer; \\
Lymph Nodes; \\
Metaplasia; \\
Cysts; \\
Immunohistochemistry; \\
BRAF Protein; \\
TP63 Protein; \\
TTF1 Protein \\
\hline
\end{tabular}

\section{Article Info}

Received 25 Oct 2016;

Accepted 03 May 2017;

Published Online 17 July 2018;

\begin{abstract}
Squamous cell differentiation (SCD) may occur in papillary thyroid carcinoma (PTC) only at metastatic sites.

We have studied cytokeratin CK5/6 and P63 along with TTF1 (thyroid transcription factor 1) and B-Raf(V-Raf murine sarcoma viral oncogene homolog B1) immunohistochemical expression in neck lymph node metastases of thyroid PTC showing SCD.

The patient (21-years) presented with a neck mass. The check-up revealed bilateral thyroid nodules. Total thyroidectomy and neck lymph node dissection were performed. The diagnosis was that of bilateral PTC with lymph node metastases (pT$1 \mathrm{~N} 1 \mathrm{Mx}$ ). The metastases were peculiar by the presence of cystic change and of SCD. The thyroid PTC expressed P63 focally and, TTF1 and B-Raf diffusely. Cytokeratin $5 / 6$ was expressed only in the lymph node metastases, in the metastatic cyst lining and in the SCD foci. The P63+ cells outnumbered those CK5/6+. TTF1 expression was faint in SCD. Metastatic, both classical PTC- and SCD-epithelia expressed B-Raf.

The expression patterns of CK5/6, P63, TTF1 suggest a luminal/central-to-abluminal/peripheral direction for SCD development from PTC-epithelia in lymph node metastases. Whether this metaplasia type may reflect a regression to a less aggressive morphotype or a progression-switch to squamous cell carcinoma-type differentiation in a composite tumor remains matter of debate.
\end{abstract}

Adriana Handra-Luca, MD PhD, APHP GHU Avicenne, Bobigny, France. E-mail: adriana.handra-luca@, aphp.fr , adriana.handra-luca@hotmail.com

Copyright (C) 2018, IRANIAN JOURNAL OF PATHOLOGY. This is an open-access article distributed under the terms of the Creative Commons Attribution-noncommercial 4.0 International License which permits copy and redistribute the material just in noncommercial usages, provided the original work is properly cited.

\section{Introduction}

Squamous cell differentiation (SCD) may occur in papillary thyroid carcinoma (PTC) not only in the lymph node metastases but also in lung metastasis (15). The morphological features of the PTC-associated SCD and the occurrence at metastatic sites may render the differential diagnosis between squamous cell metaplasia and a well differentiated squamous cell carcinoma difficult as based only on classical morphological elements (6). The demonstration of BRAF mutations may be a useful tool in ruling out a metastasis of a squamous cell carcinoma (1).

We aimed to study cytokeratin (CK) 5/6 and P63 immunohistochemical expression patterns in neck lymph node metastases of PTC showing SCD and their relationships to morphological features and
TTF1, thyroglobulin and B-Raf expression.

\section{Case Report}

The patient (woman, 21-years old) presented with a neck mass. The medical history revealed syrop allergy (type non-available) and treatment with valacyclovir for recurrent labial herpes (1-year before). The check-up revealed bilateral thyroid nodules. The thyroid function serum tests results are noted in Table 1.

A total thyroidectomy with neck lymph node dissection was performed. The thyroid tumor was a bilateral PTC (7.5- and 14.5-mm in the left and right lobes, respectively) with papillary and vesicular architecture (stage pT1N1Mx). The microscopy analysis also showed multifocal thyroiditis and a neck thymusparathyroid unit. Radioactive iodide and substitutive thyroid hormone treatments were given. 
The 2 thyroid PTCs and lymph node metastases were studied for CK5/6, P63, TTF1, thyroglobulin and B-Raf immunohistochemical expression. The immunohistocemical study results are noted in Table 2.

Table 1. Thyroid-related serum tests results.

\begin{tabular}{ccc}
\hline Serum tests & Actual value & Normal value \\
\hline TSH & $\mathrm{mIU} / \mathrm{L} 0.81$ & $0.35-4.94$ \\
\hline Anti-thyroperoxidase antibody & $\mathrm{IU} / \mathrm{mL} 8$ & $34>$ \\
\hline Anti-thyroglobulin antibody & $\mathrm{IU} / \mathrm{mL} 106$ & $115>$ \\
\hline Calcitonin & 'ng/L 2 & $5>$ \\
\hline
\end{tabular}

Table 2. Immunophenotype of primary and metastatic tumors (PTC papillary thyroid carcinoma, SCD squamous cell differentiation).

\begin{tabular}{cccc}
\hline $\begin{array}{c}\text { Protein detected by im- } \\
\text { munohistochemistry }\end{array}$ & $\begin{array}{c}\text { Primary tumor } \\
\text { (thyroid PTC) }\end{array}$ & $\begin{array}{c}\text { Lymph node metastases } \\
\text { PTC }\end{array}$ & $\begin{array}{c}\text { Lymph node metastases } \\
\text { SCD }\end{array}$ \\
\hline Cytokeratin 5/6 & Absent & Present (focally) & Present \\
P63 & Present (focally) & Present (focally) & Present \\
TTF1 & Present & Present & Present \\
Thyroglobulin & Present & Present & Present \\
B-Raf & Present & Present & Prent \\
\hline
\end{tabular}

The thyroid PTC expressed focally P63 and diffusely TTF1, thyroglobulin and B-Raf (Figure 1).

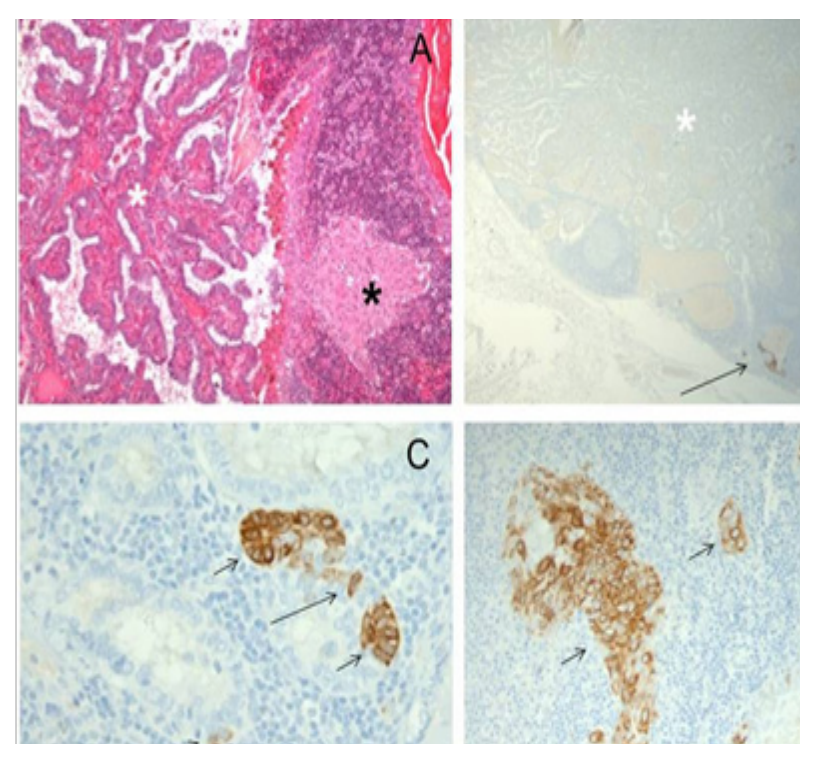

Figure 1. The lymph node metastasis of papillary thyroid carcinoma (PTC) showed compact squamous cell differentiation (SCD) foci with transition zones to the cystic zones (A: black asterisk for SCD, white asterisk for PTC).

The cytokeratin CK5/6-positive foci were sparse and less abundant than the classical PTC metastatic tissue (B: black arrow for CK5/6-positive zone, white asterisk for PTC). The CK5/6-positive cells were of cubo-cylindric nondescript- or large squamoid-type; uni- or pluristratified (C,D: long arrow for isolated cells, short arrow for cell groups). Original magnification x2.5 (B), x10 (A,D) x40 (C).
CK5/6 was not expressed by the thyroid PTCs consistent with the lack of solid foci on the hematoxylin and eosin (HE) slides. SCD was observed only in the metastatic lymph nodes (15 of the 19 metastatic lymph nodes). 11 of the metastases with SCD were cystic (ranges 1-17.5-mm) out of the 14 cystic metastatic lymph nodes in total. The SCD foci were observed in the cyst lining and pericystically as compact cell groups or microcysts, with focal transition to the large cyst lining (Figure 1). Keratin was present in one of the SCD foci while dyskeratosis in several. The SCD epithelium was at direct contact to the lymph node parenchyma, without interposition of fibrotic capsule or stroma. CK5/6 (immunohistochemistry performed on two tissue slides of lymph node metastases) was expressed in a multifocal pattern, overlapping to that of the SCD epithelial foci seen on the HE-slides. Positive cubic or flat cells located basally and suprabasally (and not luminally), disposed in uni- or pluristratified epithelia, lined the cystic zones of the metastases. CK5/6 was also expressed, heterogeneously, in compact cell groups, by large squamoid cells around the cysts as well as in small metastatic PTC-vesicles, by small undifferentiated/ nondescript cells (sparse or grouped). Cells express- 
ing nuclear P63 in the SCD foci, outnumbered those CK5/6-positive (Figures 2,3).
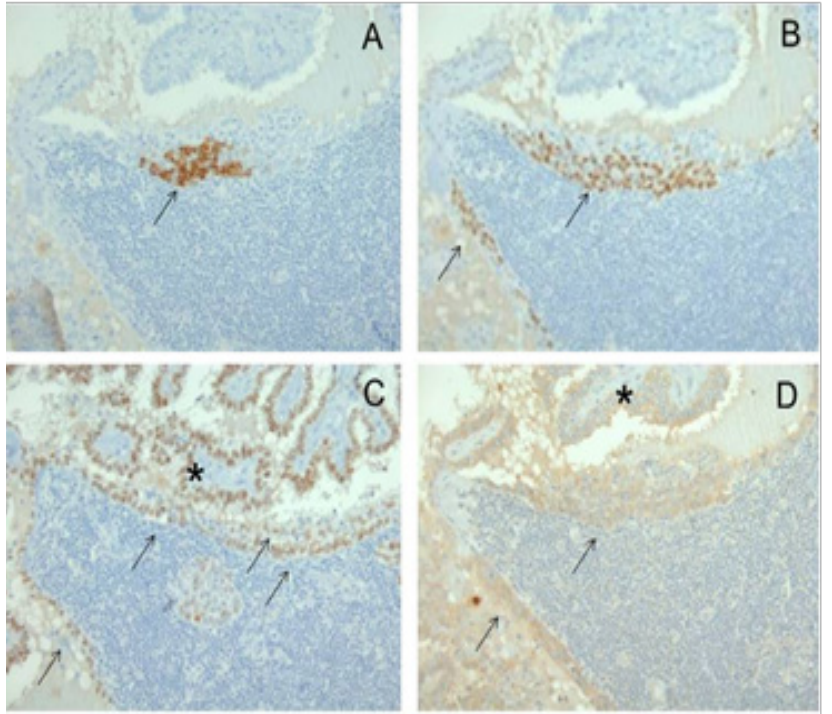

Figure 2. The lymph node metastases, the foci of CK5/6-positive cells were basally and suprabasally located (A: black arrows). The cells expressing P63 were more numerous (B: black arrows for P63-positive cells; asterisk for P63-negative PTC foci). TTF1 was expressed in the SCD with a uni- or pluristratified pattern, including by luminal cells (C: black arrows for TTF1-positive SCD, asterisks for TTF1-positive PTC). B-Raf was expressed diffusely in the PTC and the SCD foci (D: arrows for SCD, asterisks for PTC). Original magnification x20 (A-D).

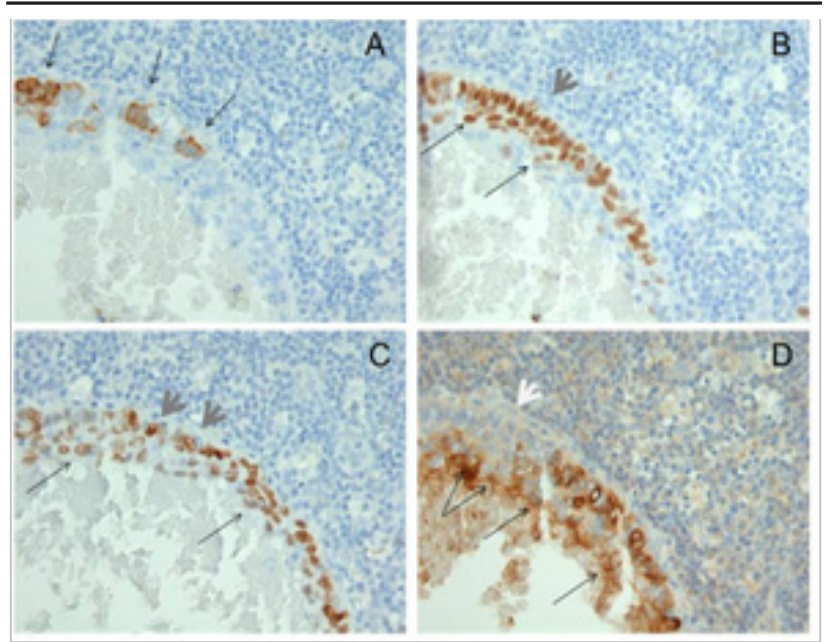

Figure 3. In another cystic structure of lymph node metastases, basal and suprabasal expression of CK $5 / 6$ was seen (A: black arrows). P63 was expressed more diffusely, with a basal palisading pattern (B: black arrows for SCD expression, grey arrow for basal palisading). There was no intervening stroma at the interface with the lymph node tissue. While TTF1 was expressed in the entire thickness of the SCD epithelium, including in luminal cells (C: black arrows), thyroglobulin was expressed heterogeneously, including in basal cells (D: arrows, white arrow for thyroglobulin-negative basal cells). Of note would be the lack of TTF1 in ground-glass appearing nuclei (C: grey arrows). Original magnification $\mathrm{x} 40$ (A-D).
P63 expression was strong in the SCD foci, with focal palisading at the interface with the lymph node parenchyma, and frequently absent in the luminal cells. In the classical PTC metastatic foci, P63 expression was mild, in sparse cells. TTF1 expression was moderate to mild and focal in the SCD epithelium, as compared to the expression in the classical PTC metastatic cells (Figures 2,3,4).

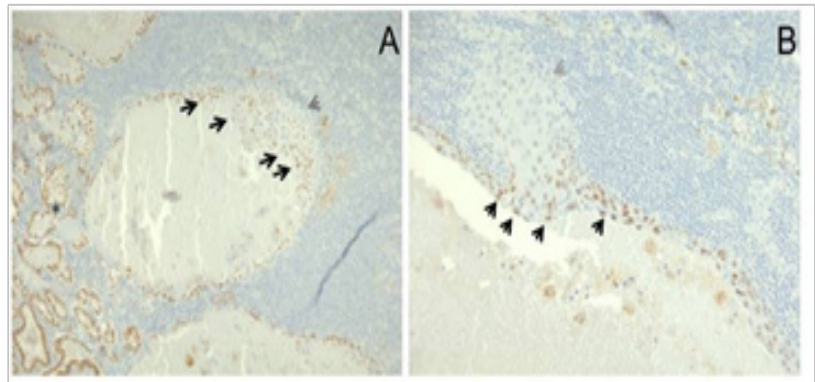

Figure 4. In lymph node metastases, TTF1 was expressed in the $\mathrm{SCD}$, however showing a progressive decrease in intensity (A: black arrows for TTF1-positive SCD; asterisk for TTF1-negative SCD) with a uni- or pluristratified pattern, including by luminally situated cells (A,B: grey arrows). Original magnification x10 (A,B).

However TTF1 positive nuclei were seen in the luminal cells, above the CK5/6-positive and P63-positive cells in the SCD foci. Thyroglobulin immunohistochemistry was heterogeneous, including in the TTF1 positive foci (Figure 3).

Cytoplasmic B-Raf immunohistochemical expression (with membrane accentuation) was seen both in metastatic PTC and SCD epithelial cells (Figure 2).

\section{Discussion}

The expression in lymph node metastases of B-Raf in the classical PTC and SCD cells along with the presence of transition zones between the metastasis cyst lining and compact foci of SCD; along with the reduced amount of SCD foci in comparison to the classical PTC-metastasis foci as well as along with the persistence (however with a progressive loss of intensity) of TTF 1 expression, were suggestive of the development of SCD from the metastatic PTC cells. Whether the recurrent herpes infections observed in the present case might have impacted on the occurrence of SCD remains hypothetical. Of interest would be the fact that virus immortalized lines, but of the S-40-virus, are considered to undergo a differentia- 
tion switch similar to the variant squamoid thyroid cell subpopulations reported by Bond (7). Herpesvirus DNA may be identified in thyroid autoimmune disease $(8,9)$. In the case we report objective arguments for a possible herpes-virus involvement or co-involvement are difficult to determine except for the presence of the multifocal lymphocytic thyroiditis lesions. The possible impact of homologies of the thyroid sodium-iodide symporter with thyroglobulin-, thyroperoxidase- as well as with/or viral antigens of herpes-virus type remains to be further investigated (10).

The occurrence of morphologically benign or immature SCD foci, lacking the squamous cell carcinomacaracteristic nucleo-cytoplasmic atypia, in relationship with a metastatic PTC in lymph nodes, similarly to the SCD occurring in primary PTC or, to the squamous morulae or SCD in endometrioid carcinoma, remains a matter of debate (5). Besides the fact that the morphological features in the case we report, were suggestive of a non-glandular differentiation, these features were also suggestive of a reversion to a less aggressive nucleocytoplasmic morphotype with an abundant cytoplasm or with unidentifiable intercellular bridges and, with only mild nuclear irregularities. However, of note would be that a high proliferative capacity in vitro is reported for the variant epithelial, normal thyroid subpopulation showing squamoid morphology, rendering plausible the hypothesis of progression to a squamous cell carcinoma morphotype (7).

Another point of interest might be the increased number of P63-positive cells as compared to that of CK5/6-positive cells, in agreement with the known protein sequence of squamous development and with the role of P63 in de novo biosynthesis/expression of CK5/6 (11,12). Interestingly TTF1-positive nuclei, although less intensely stained as compared to those of PTC cells, were seen in the entire thickness of SCD foci, including in the luminal layer, above the CK5/6positive and P63-positive cells, suggesting a luminal/ central-to-abluminal/peripheral direction in the development of SCD in PTC, from the extensively and strongly TTF1-positive, rarely P63-positive, PTC epithelium to the SCD epithelium showing mild to moderate TTF1 and, predominantly, basal P63 and de novo CK5/6 expression. Whether the gain of CK5/6 and P63 and decrease of TTF1 expression in intratumor/intrametastatic stem/reserve cells, are pivotal for the observed intra-lymph node parenchyma invasiontype development of SCD (focally of solid morphological pattern) from metastatic, classical PTC glandular foci, remains to be further investigated.

B-RAF mutation detection may be pivotal in the diagnosis of PTC metastases (1). Immunohistochemistry for B-Raf could be also considered, although more relevant for the heterogeneity of PTC metastases. While the co-expression of B-Raf and TTF1 we have observed in PTC cells paralleled that observed in lung adenocarcinomas (5), the co-expression B-Raf and P63 was in agreement with data on benign thyroid lesions not only of adenoma type but also of solid cell nest-type (pericarcinomatous however), which express P63, CK5/6 and may show B-RAF mutation $(13,14)$. Whether B-Raf-inhibitors may be effective in such heterogeneous PTC, with SCD, remains to be investigated, hyperkeratosis and cutaneous SCC being reported as adverse reactions (15).

In conclusion, the expression patterns in lymph node metastases of CK5/6, P63 and TTF1 in the PTC and SCD epithelia, suggest a luminal/central-to-abluminal/peripheral direction for SCD development from PTC epithelium. Whether this metaplasia type may reflect a regression to a less aggressive morphotype or a progression-switch to squamous cell carcinoma differentiation in a composite tumor remains to be further studied.

\section{Acknowledgment}

The author thanks Pr D Thomas, Dr F Combes, Dr I Keller-Petrot, Dr ML Dumuis-Gimenez, I Alexandre, M Rodrigues, S El Sayeh, J Raleche, V Guzal, C Van Vetteren, I Pluchart, L Jovanov, F Spindler, B Mechekour, N Delva, F Bouchard, F Aurejac, B Mechekour, M De Souza, MC Portenier, P Chenoux ainsi que les Laboratoires de Biologie Medicale des Franciliens et Cerba, NCA/APHP Avicenne, BIUM, 
CDMP/APHP et Bibliotheque des Hopitaux des Armées Val de Grace.

\section{Conflict of interests}

The authors declared no conflict of interest.

\section{References}

1. Acosta AM, Pins MR. Papillary thyroid carcinoma with extensive squamous dedifferentiation metastatic to the lung: BRAF mutational analysis as a useful tool to rule out tumor to tumor metastasis. Virchows Arch 2016;468(2):239-

42. https://doi.org/10.1007/s00428-015-1875-8

2. Harada T, Shimaoka K, Katagiri M, Shimizu M, Hosoda Y, Ito K. Rarity of squamous cell carcinoma of the thyroid: autopsy review. World J Surg 1994;18(4):542-6. https://doi.org/10.1007/

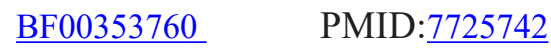

3. Katoh R, Sakamoto A, Kasai N, Yagawa K. Squamous differentiation in thyroid carcinoma. With special reference to histogenesis of squamous cell carcinoma of the thyroid. Acta Pathol Jpn. 1989;39(5):306-12. https://doi. org/10.1111/j.1440-1827.1989.tb02440.x

4. Klinck GH, Menk KF. Squamous cells in the human thyroid. Mil Surg. 1951;109(4):406-14. https://doi.org/10.1093/milmed/109.4.406

5. Rosai J. Rosai and Ackerman's Surgical Pathology. 10ed. Philadelphia PA: Elsevier; 2011.

6. Kunisue H, Mikami Y, Tanaka K, Sonoo H, Udagawa K, Yamamoto Y, et al. Metastatic papillary thyroid carcinoma of the submandibular lymph nodes with extensive squamous metaplasia: report of a case. Surg Today. 2003;33(10):751-4. https://doi.org/10.1007/ s00595-003-2581-8 PMID:14513322

7. Bond JA, Wyllie FS, Ivan M, Dawson T, Wynford-Thomas D. A variant epithelial subpopulation in normal thyroid with high proliferative capacity in vitro. Mol Cell Endocrinol. 1993;9(2):175-83. https://doi.org/10.1016/03037207(93)90121-Y

8. Jensen K, Patel A, Larin A, Hoperia V, Saji M, Bauer A, et al. Human herpes simplex viruses in benign and malignant thyroid tumours. J Pathol.
2010;221(2):193-200. https://doi.org/10.1002/ path.2701 PMID:20455254

9. Thomas D, Liakos V, Michou V, Kapranos N, Kaltsas G, Tsilivakos V, et al. Detection of herpes virus DNA in post-operative thyroid tissue specimens of patients with autoimmune thyroid disease. Exp Clin Endocrinol Diabetes. 2008;116(1):35-9. https://doi.org/10.1055 /s-2007-956171 PMID:18240111

10. Benvenga S, Alesci S, Trimarchi F, Facchiano A. Homologies of the thyroid sodium-iodide symporter with bacterial and viral proteins. J Endocrinol Invest. 1999;22(7):535-40. https://doi. org/10.1007/BF03343605 PMID:10475151

11. Rausch T, Benhattar J, Sutter M, AndrejevicBlant S. Thyroid carcinoma with papillary and squamous features: report of a case with histogenetic considerations. Pathol Res Pract. 2010;206(4):263-9. https://doi.org/10.1016/j. prp.2009.05.003 PMID:19493635

12. Romano RA, Ortt K, Birkaya B, Smalley K, Sinha $\mathrm{S}$. An active role of the DeltaN isoform of p63 in regulating basal keratin genes K5 and K14 and directing epidermal cell fate. PLoS One. 2009;4(5):e5623. https://doi.org/10.1371/ journal.pone.0005623 PMID:19461998

13. Cameselle-Teijeiro J, Abdulkader I, PérezBecerra R, Vázquez-Boquete A, Alberte-Lista $\mathrm{L}$, Ruiz-Ponte $\mathrm{C}$ et al. BRAF mutation in solid cell nest hyperplasia associated with papillary thyroid carcinoma. A precursor lesion? Hum Pathol. 2009;40(7):1029-35. https://doi. org/10.1016/j.humpath.2008.11.015

14. Soares P, Trovisco V, Rocha AS, Lima J, Castro $\mathrm{P}$, Preto A, et al. BRAF mutations and RET/ PTC rearrangements are alternative events in the etiopathogenesis of PTC. Oncogene. 2003;22(29):4578-80. https://doi.org/10.1038/ sj.onc.1206706 PMID: 12881714

15. Nowara E, Huszno J, Slomian G, Nieckula J. Skin toxicity in BRAF(V600) mutated metastatic cutaneous melanoma patients treated with vemurafenib. Postepy Dermatol Alergol. 2016;33(1):52-6. https://doi.org/10.5114/ pdia.2015.48045 PMID:26985180

\section{How to Cite This Article}

Handra-Luca A. Squamous Cell Differentiation in Metastatic Papillary Thyroid Carcinoma: Metaplastic. Iranian Journal of Pathology, 2018; 13(2): 276-280. 